\title{
Weichgewebssarkome: Interdisziplinäre Behandlungsansätze
}

\author{
Interdisciplinary Treatment of Soft Tissue Sarcomas
}

Die ausgesprochene Heterogenität, ein mögliches Wachstum fast überall im Körper, die Seltenheit und das Auftreten in praktisch jedem Lebensalter lassen die Weichgewebssarkome weiterhin als eine enorme Herausforderung erscheinen und bedürfen differenzierter Behandlungsansätze. Wie kaum eine andere Tumorart erfordern Weichgewebssarkome interdisziplinäre Fachexpertise, die heute nur in einem Tumorboard im spezialisierten Zentrum vorgehalten werden kann. Die Behandlung kindlicher Weichgewebssarkome belegt vorbildhaft die Rolle dieser Zentren.

Leider zeigt die systemische Therapie bei Weichgewebssarkomen trotz immer wieder neuer Substanzen weiterhin nur geringe Ansprechraten. Die Bestrahlung erhöht die lokale Sicherheit, wirkt sich aber nicht auf das Gesamtüberleben aus. Die Übersichtsarbeit von Kraus-Tiefenbacher und Mitarb. zeigen dennoch eindrücklich die Fortschritte in der Bestrahlungstherapie.

Die onkologiegerechte Resektion (R0) mit gesundem Gewebesaum stellt weiterhin die wichtigste Maßnahme im Stadium der lokalisierten Erkrankung dar. Daigeler und Mitarb. zeigen, dass diese Grundsätze auch bei Auftreten einer Rezidiverkrankung Gültigkeit behalten. Noch immer in Büchern aufgeführte Sicherheitsabstände von mehreren Zentimetern sind prognostisch nicht mit längerem Überleben kombiniert und somit nicht mehr haltbar. Die Arbeitsgruppe um Steinau und Mitarb., welcher sicherlich als „der“ Pionier der Extremitäten-erhaltenden Tumorresektion in Deutschland anzusehen ist, belegen an ihrer Serie zu Sarkomen an Hand und Unterarm, dass in den großen Zentren die Amputationsraten heute unter $3 \%$ liegen.

Die moderne Plastisch-Rekonstruktive Chirurgie mit ihrem immer umfangreicheren Spektrum mikrochirurgischer Verfahren bietet ein enormes Potenzial zur Wiederherstellung der betroffenen Extremitäten ohne Amputation.

Die Arbeit von Marco Innocenti und Mitarb. zur Radiusrekonstruktion, von Engelhardt und Mitarb. zur anatomischen Rekonstruktion und von Wiebringhaus und Mitarb. zu sekundären Tumoren wie dem meist strahleninduzierten Angiosarkom der Brust belegen dies eindrucksvoll.

Die Arbeitsgruppe aus Münster demonstriert am Beispiel der Knochensarkomen, dass gelebte Interdisziplinarität heute der Hauptschlüssel zum Behandlungserfolg in der Sarkomtherapie darstellt. Die Übersichtsarbeit aus Frankfurt zur Rekonstruktion der unteren Extremität beleuchtet die manigfaltigen Therapieoptionen in dieser Region, selbst bei Säuglingen.

Liebe Leserinnen und Leser, wir freuen uns, Ihnen ein interessantes Themenheft mit einem umfassenden Update zur Sarkomtherapie, präsentieren zu können.

Frankfurt, Bochum und München im Februar 2015

Michael Sauerbier, Marcus Lehnhardt, Riccardo E. Giunta
Bibliografie

DOI http://dx.doi.org/ $10.1055 / \mathrm{s}-0035-1548774$ Handchir Mikrochir Plast Chir 2015; $47: 75$

(c) Georg Thieme Verlag KG Stuttgart · New York ISSN 0722-1819

Korrespondenzadresse Prof. Dr. med. Dr. med. habil. M. Sauerbier Chefarzt Abteilung für Plastische Hand- und Rekonstruktive Chirurgie

Hand-Trauma-Zentrum Berufsgenossenschaftliche Unfallklinik Frankfurt am Main Friedberger Landstraße 430 60389 Frankfurt am Main michael.sauerbier@bgufrankfurt.de

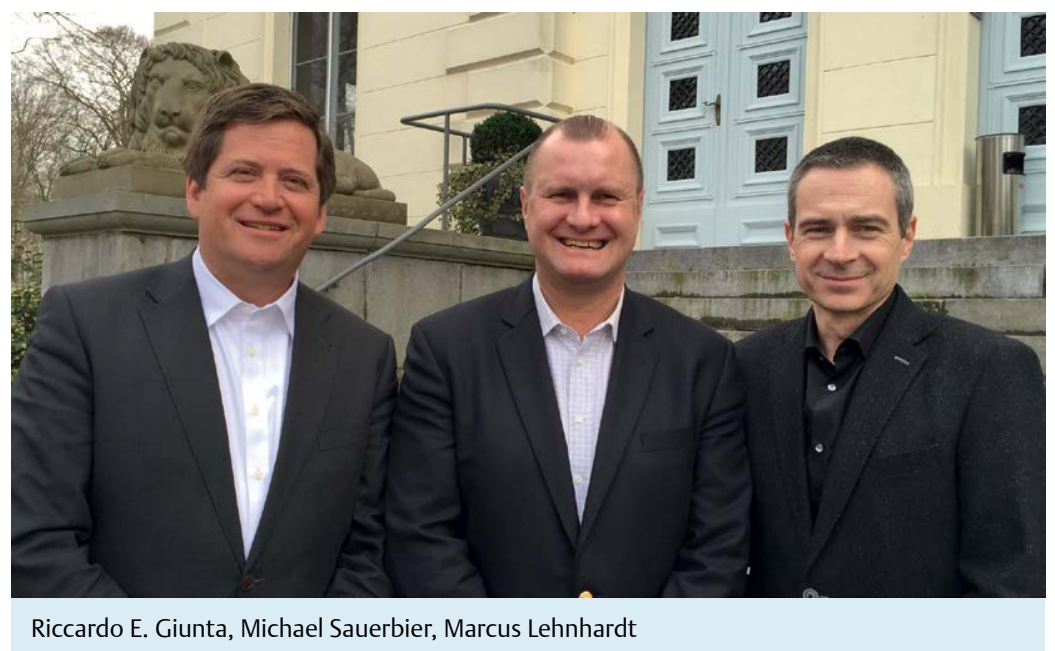

